\title{
Seismic Design of Foundations
}


Downloaded by [] on [25/04/23]. Copyright (C) ICE Publishing, all rights reserved. 


\section{Seismic Design of Foundations Concepts and applications}

\section{Subhamoy Bhattacharya}

University of Surrey, United Kingdom

\section{Rolando P Orense}

The University of Auckland, New Zealand

\section{Domenico Lombardi}

The University of Manchester, United Kingdom 
Published by ICE Publishing, One Great George Street, Westminster, London SW1P 3AA.

Full details of ICE Publishing representatives and distributors can be found at: www.icebookshop.com/bookshop_contact.asp

\section{Other titles available from ICE Publishing:}

Earthquake Design Practice for Buildings, Third edition.

Edmund Dwight Booth. ISBN 978-0-7277-5794-4

Designers' Guide to Eurocode 8: Design of bridges for earthquake resistance

Basil Kolias, Michael N. Fardis and Alain Pecker. ISBN 978-0-7277-5735-7

Shock Transmission Units in Construction

Dinesh J. Patel. ISBN 978-0-7277-5713-5

www.icebookshop.com

A catalogue record for this book is available from the British Library

ISBN 978-0-7277-6166-8

(C) Thomas Telford Limited 2019

ICE Publishing is a division of Thomas Telford Ltd, a wholly-owned subsidiary of the Institution of Civil Engineers (ICE).

All rights, including translation, reserved. Except as permitted by the Copyright, Designs and Patents Act 1988, no part of this publication may be reproduced, stored in a retrieval system or transmitted in any form or by any means, electronic, mechanical, photocopying or otherwise, without the prior written permission of the Publisher, ICE Publishing, One Great George Street, Westminster, London SW1P 3AA.

This book is published on the understanding that the author is solely responsible for the statements made and opinions expressed in it and that its publication does not necessarily imply that such statements and/or opinions are or reflect the views or opinions of the publishers. While every effort has been made to ensure that the statements made and the opinions expressed in this publication provide a safe and accurate guide, no liability or responsibility can be accepted in this respect by the author or publishers.

While every reasonable effort has been undertaken by the author and the publisher to acknowledge copyright on material reproduced, if there has been an oversight please contact the publisher and we will endeavour to correct this upon a reprint.

Cover photo: Kobe, Japan; March 2009. Preserved crater from 1995 Great Hanshin Earthquake.

Commissioning Editor: James Hobbs

Production Editor: Madhubanti Bhattacharyya

Marketing Specialist: April Asta Brodie

Typeset by The Manila Typesetting Company

Index created by Laurence Errington

Printed and bound in Great Britain by TJ International, Padstow 
01

Introduction to earthquake geotechnical engineering in relation to foundation design

1.1. Introduction

1.2. Overview of earthquake engineering

1.3. What does earthquake geotechnical engineering cover?

1.4. Examples of geotechnical damage

1.5. Major topics in earthquake geotechnical engineering

1.6. Historical perspective: how engineers learnt from earthquakes 13

1.7. Complexity of earthquake geotechnical engineering 29

1.8. Summary 32

References

02

Basic concepts of engineering seismology and seismic hazard analysis

2.1. Introduction

2.2. Theories of plate tectonics and elastic rebound

2.3. Types of faults

2.4. Evaluation of earthquake size

2.5. Hazards for the seismic design of foundations

2.6. Seismic hazard analysis

2.7. Case study: damage to the outlet tunnel of the second Kakkonda hydropower station (This case study is based on the seminal work of Prof Konagai, see for further details Konagai (2005), Johansson and Konagai (2007))

2.8. Case study: quantification of the PGA for locations in India where strong-motion records are unavailable

2.9. Quantification of fault movement

2.10. Case study: hazard to pipelines due to permanent ground deformations

2.11. Quantification of the duration of an earthquake

2.12. Summary

References

03

Selection of strong motion for foundation design

3.1. Introduction

3.2. Background to the problem

3.3. Criteria for the selection of earthquake records

3.4. Methods for spectral matching

3.5. Case study: application of spectrum-compatible input motion

3.6. Summary

References

04

\section{Ground response analysis}

4.1. Introduction

4.2. Seismic wave propagation in layered media 81

4.3. Methods of ground response analysis 83

4.4. Linear ground response analysis procedure 84 


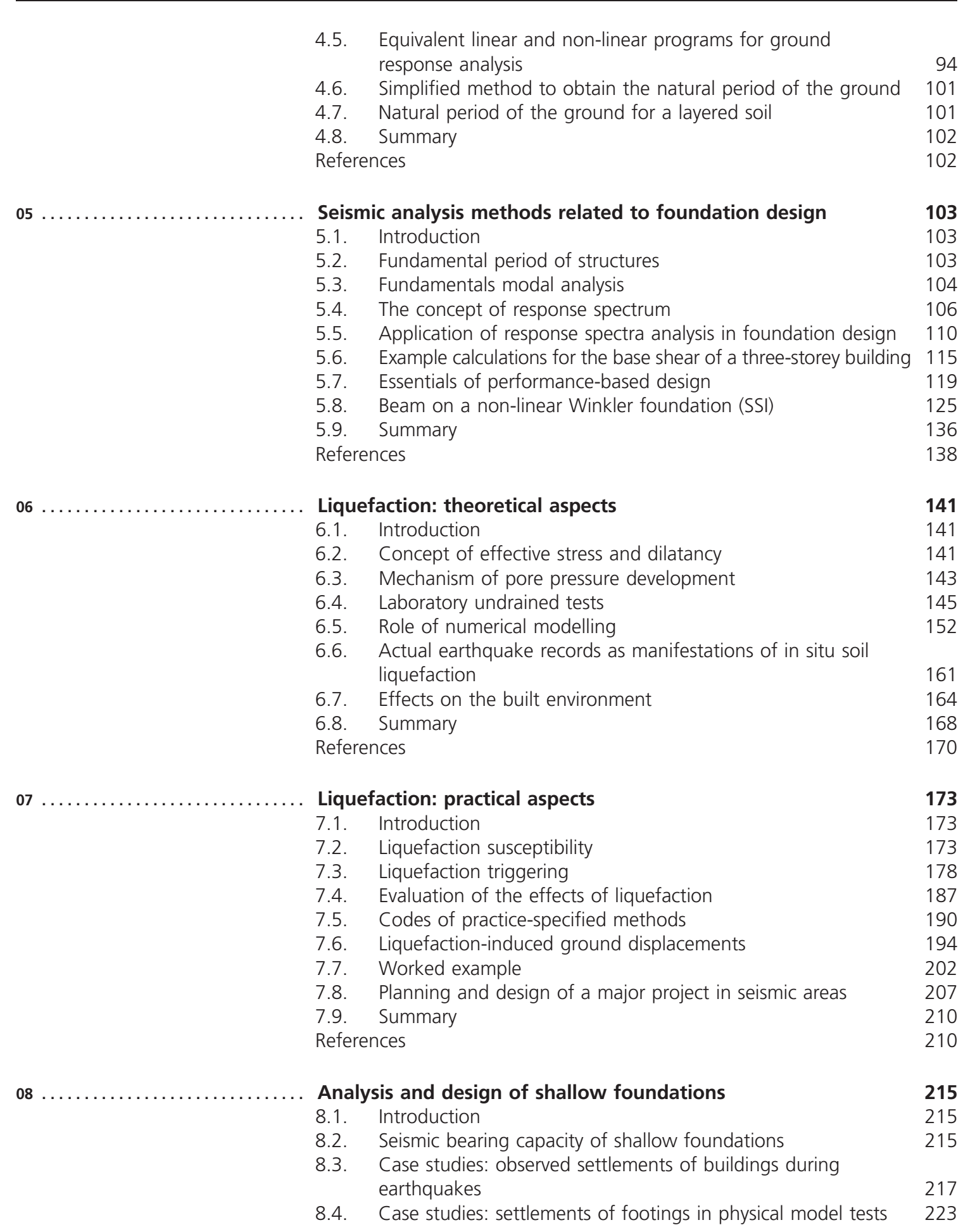




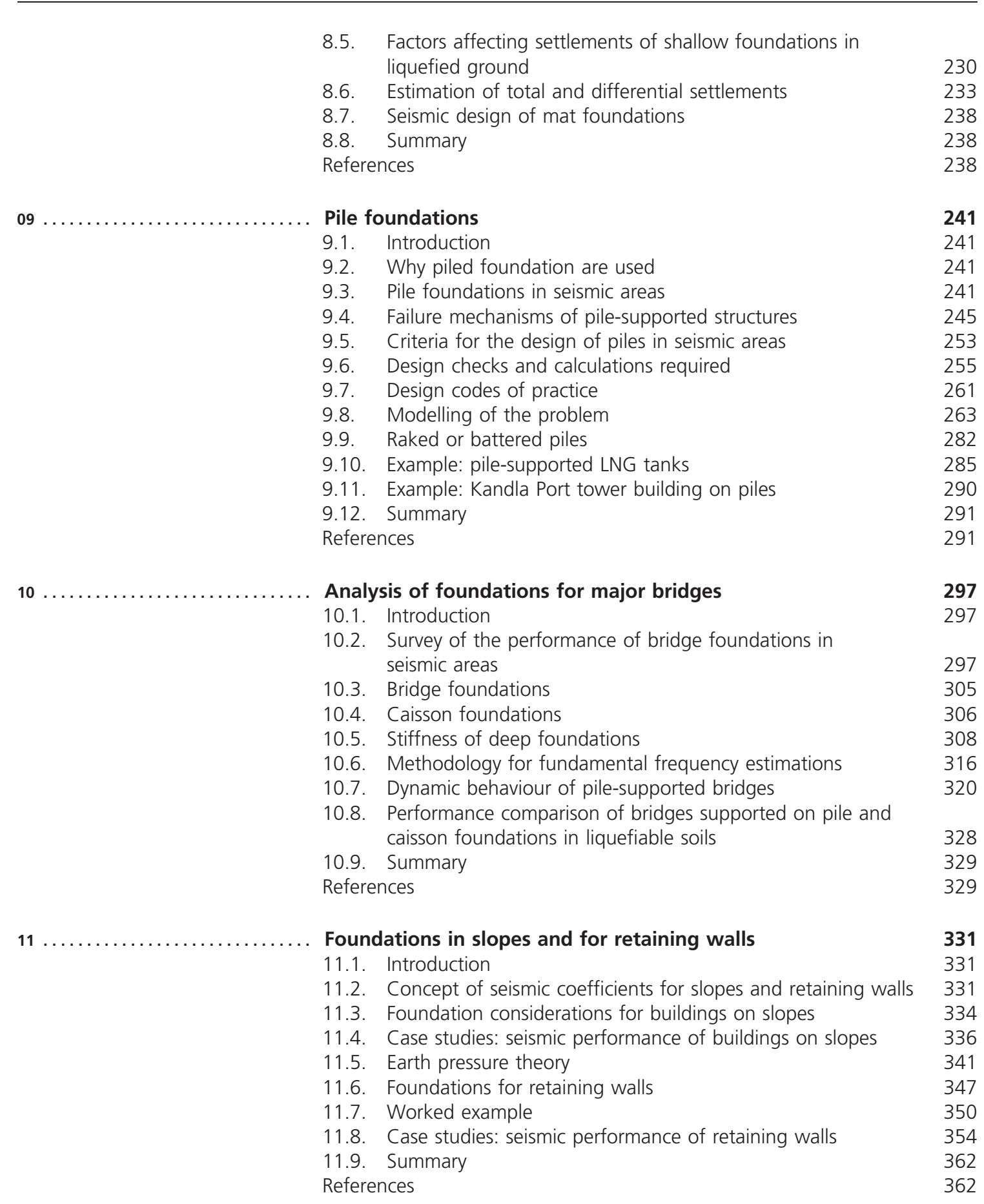


$12 \ldots \ldots \ldots \ldots \ldots \ldots \ldots \ldots \ldots$ Liquefaction countermeasures 365

12.1. Introduction 365

12.2. Liquefaction countermeasures 365

12.3. Ground improvement methods 369

12.4. Analysis and design of typical ground improvement methods 377

12.5. Worked examples for typical methods 386

12.6. Case studies: ground improvement method application $\quad 389$

12.7. Case studies: seismic performance of improved-ground sites 395

12.8. Methods to strengthen shallow foundations 409

12.9. Methods to strengthen pile foundations 414

12.10. Summary 417

References 417

Appendix $\ldots \ldots \ldots \ldots \ldots \ldots \ldots$ Engineering correlations for the design of foundations 421

$\begin{array}{ll}\text { Index } & 451\end{array}$ 


\section{Preface}

In order to carry out design of foundations in seismically active areas, one requires some level of expertise in seismic hazard assessment, soil behaviour under cyclic loading, structural dynamics and soil-structure interaction, in addition to standard foundation analysis and design concepts. As a result, this subject initially emerged as a specialist area for only a few researchers as well as a handful of professional engineering consultants, although over the years, it has gradually appeared on specialist undergraduate and postgraduate courses at many universities.

The flow (that is, the structure) of the book follows a pattern that would be typical of a design process: assessment and quantification of seismic hazards that would affect foundation design (Chapters 2 to 7), followed by design and mitigation aspects. The design of foundations requires a fundamental understanding of probabilistic concepts of seismic hazards, ground response analysis and structural analysis, and these subjects can themselves be the subjects of an entire book. Therefore, only the necessary analysis and design concepts - including, but not limited to, response spectra, modal analysis, beam on Winkler foundations, and ground response analysis - are covered in brief, and only the fundamentals are explained, along with some examples. Wherever possible, references are provided for further reading. The authors have sincerely attempted to make the book as useful and practicable as possible by providing case studies, example applications, and solved examples from the real world.

The $11^{\text {th }}$ March 2011 Tōhoku earthquake (Japan) was a rare and a landmark event which can be described as an act of war between nature and earthquake engineers. It is fair to say that if the effects of the tsunami are discounted, the overall performance of the structures under the action of earthquake (together with liquefaction) shows that there is a lot to learn from Japanese earthquake geotechnical engineers. The first author (Professor Bhattacharya) was in Japan on that day and had first-hand experience of the performance of these structures. Following the 2010-2011 Canterbury earthquake sequence (New Zealand), the second author (Associate Professor Orense) worked over a period of more than 18 months to investigate the impact of ground shaking and soil liquefaction on the built environment of Christchurch and surrounding areas. This book heavily draws upon the experiences of these two recent earthquakes, as well as from lessons learned in other recent large-scale earthquakes.

The book is born out of research by the authors as well as postgraduate and CPD (Continuing Professional Development) teaching and specialist lectures they delivered at various universities and organisations. Examples include: Professor Bhattacharya's courses on earthquake engineering at the University of Surrey (MSc course) and University of Bristol (MEng course) in the UK, Indian Institutes of Technologies (IIT Kharagpur 
and IIT Bhubaneswar as a part of ISWT (International Summer and Winter Term) and GIAN (Global Initiative for Academic Networks) courses respectively), ASRANet CPD courses in Delft, London and Brussels as well as at Yamaguchi University and Tokyo Institute of Technology (Japan), Zhejiang University (China), Tongji University (China) and Harbin Institute of Technology (China). Associate Professor Orense (second author) provided lectures on the same topic at the University of Auckland (New Zealand), University of Tokyo and Yamaguchi University (Japan), the University of the Philippines and through technical workshops and seminars sponsored by the Engineering New Zealand (EngNZ) held in various cities in New Zealand.

It is hoped that this book will be ideal for any student studying postgraduate geotechnical engineering or structural engineering, as well as researchers and practitioners working in the field of earthquake geotechnical engineering. Due to the changing requirements in the current technological age and market demands of the modern educational system, ICE Publishing wishes to make individual chapters of the book available to readers through its e-book platform ICE Virtual Library. Therefore, to make each chapter self-sufficient, there are some inevitable repetitions of some figures and textual analysis.

This field of engineering is constantly evolving as each major earthquake teaches us something new. Many of the methodologies or calculation procedures presented here may become outdated or be modified in the next few years, at which point this book may require a new edition. There may also be errors and omissions in the book and we would be grateful if those were brought to our attention. Please email the authors at Subhamoy.Bhattacharya@gmail.com or r.orense@auckland.ac.nz and the comments will be duly acknowledged in the next edition.

Subhamoy Bhattacharya

Rolando P Orense

Domenico Lombardi 
Acknowledgements

The authors are grateful for the contributions of the many people who helped make this book a reality. Individually and collectively, they benefitted from close association with various researchers in drawing experiences for this book: Gopal Madabhushi and Malcolm Bolton (University of Cambridge), Tony Blakeborough, Harvey Burd and Martin Williams (University of Oxford), Kazuo Konagai (Institute of Industrial Science, Tokyo), Jorgen Johansson and Amir Kaynia (NGI), Nick Alexander, George Mylonakis, Colin Taylor, D Muir Wood, Erdin Ibraim (University of Bristol), Masayuki Hyodo and Gakuo Watanabe (Yamaguchi University), George Nikitas, Stefan Szyniszewski and Stergios Mitoulis (University of Surrey), Sudhir Jain (IIT Gandhinagar), Vinay Gupta, Samit Roychowdhury, Prishati Roychowdhury (IIT Kanpur), Dilip Baidya and Nilanjan Mitra (IIT Kharagpur), Indrajit Chowdhury (ex-Petrofac), Murali Krishna, Pradeep Dammala and Kaustubh Dasgupta (IIT Guwahati), T Sitharam and GLS Sivakumar Babu (IISc Bangalore), L Gobindraju (NIT, India), Sekhar Dutta, Rajib Sarkar and Sankey Nayak (IIT Dhanbad), Armando Simonelli and Luigi Di Sarno (University of Sannio, Italy), Kenji Ishihara (Chuo University), Ikuo Towhata (ex-University of Tokyo), Kohji Tokimatsu (ex-Tokyo Institute of Technology),

Deepankar Chowdhury (IIT Mumbai), Nozomu Yoshida (Tohoku Gakuin University), Mehdi Rouholamin (University of Portsmouth), Josh Macabuag (SCOR, London), Suresh Dash and Sumanta Halder (IIT Bhubaneswar), A Boominathan (IIT Madras), Rajiv Saha (NIT, Agartala), Katsu Goda (University of Western Ontario), Barnali Ghosh (Motts, UK), Ziggy Lubkowski (Arup, London), Fumio Tatsuoka (Tokyo University of Science), Susumu Yasuda (Tokyo Denki University), Susumu Iai (ex-Kyoto University), Junichi Koseki (University of Tokyo), Kenji Harada (Fudo Tetra Corporation), Tao Wang (IEM, Beijing), Yu Huang (Tongji University), the late Takashi Tazoh (Shimizu Corporation), Kenichi Soga (UC Berkeley), Andrew Chan (University of Tasmania), Michael Pender, Liam Wotherspoon and Tam Larkin (University of Auckland), Sjoerd van Balleegooy (Tonkin \& Taylor), Misko Cubrinovski and Brendon Bradley (University of Canterbury), Russell Green (Virginia Tech), Jonathan Bray (University of California Berkeley), Brady Cox and Ken Stokoe (University of Texas, Austin), Ahmed Elgamal (University of California, San Diego), Ross Boulanger (University of California, Davis), George Gazetas (NTU, Athens), Nitish Puri (NIT, India), Hironori Suzuki (Shimizu Corporation), and Amar Bouzid Djillai (Algeria).

Moreover, they would like to collectively acknowledge their close collaboration with various research institutes, funding bodies and organisations: Cambridge Commonwealth Trust, CVCP (Committee of Vice Chancellors and Principals for ORS Fellowship), Nehru Trust for Cambridge University, Junior Research Fellowship of Somerville College (Oxford University), University Research Fellowship 
(University of Bristol) NICEE and NPEEE (IIT Kanpur), and EERC

(Earthquake Engineering Research Centre, University of Bristol), RELUIS project (Department of Civil Protection, Italian Government), SERIES Project (REA, European Commission), EPSRC (Engineering and Physical Science Research Council, UK), Royal Society (UK), NSFC (National Science Foundation China), Commonwealth Spilt-Site Fellowship, Commonwealth $\mathrm{PhD}$ fellowship, Newton Funds (Newton Bhabha fellowship through British Council), UKIERI (UK India Education and Research Initiative) project, Shimizu Corporation (Japan), Hokiroku Corporation (Japan), VJTech (UK), BLADE (Bristol Laboratories for Advanced Dynamics Engineering) facilities, ARUP (UK), Motts (UK), GEER (USA), ISET (Indian Society For Earthquake Technologists), IGS (Indian Geotechnical Society), Japanese Geotechnical Society (JGS), New Zealand Geotechnical Society (NZGS), Institution of Civil Engineers (ICE), Institution of Structural Engineers (IStructE), Kiso-jiban Consultants Ltd., Japan Home Shield Corp. and Fudo Tetra Corp.. They would also like to thank their current and former postgraduate students who, in one or another, contributed to this book. Special thanks to current $\mathrm{PhD}$ students Hasan Emre Demirci, Rajesh Rele and Piyush Mohanty.

Finally, they would like to thank Amber Thomas (ex-ICE), James Hobbs, Madhubanti Bhattacharyya, and others on the ICE Publishing editorial staff who made this book possible and refined the rough draft into this finished product. 